\title{
BOURDIEU E EDUCAÇÃO: CONCEPÇÃO CRÍTICA PARA PENSAR AS DESIGUALDADES SOCIOEDUCACIONAIS NO BRASIL
}

\author{
FERREIRA, Walace ${ }^{1}$ - UERJ
}

\section{RESUMO:}

Pierre Bourdieu é, sem duvida, um dos grandes sociólogos do século XX, reconhecido internacionalmente, e um dos grandes pensadores contemporâneos a abordar a questão da educação de forma tão relevante. Neste artigo apresentamos sua teoria acerca da educação nas sociedades modernas, em que aparece uma considerável relação entre o papel da escola e a reprodução e legitimação das desigualdades sociais no contexto do capitalismo. Em seguida, propomos uma reflexão sobre alguns aspetos da desigualdade social brasileira à luz da teoria de Bourdieu, de maneira a estimular o leitor a ter um pensamento mais cuidadoso e crítico sobre a educação e o seu papel.

Palavras-Chave: Bourdieu - Concepção crítica - Desigualdade social no Brasil - Papel da educação.

\begin{abstract}
:
Pierre Bourdieu is, without doubt, one of the great sociologists of the twentieth century, recognized internationally, and one of the greatest contemporary thinkers to address the issue of education. This article presents the theory of Bourdieu on education in modern societies, in which appears a significant relationship between the school and the role of reproduction and legitimation of social inequalities in the context of capitalism. Then we propose a reflection on some aspects of Brazilian social inequality in the light of Bourdieu's theory, so as to encourage the reader to a more careful and critical thinking about education and its role.
\end{abstract}

KEYWORDS: Bourdieu - Critical conception - Social inequality in Brazil - The role of education.

"Ensinar não é transferir conhecimento, mas criar as possibilidades para a sua própria produção ou a sua construção".

\footnotetext{
${ }^{1}$ Professor Substituto de Sociologia no CAp-UERJ; Doutorando em Sociologia no IESP/UERJ. Email: walaceuerj@yahoo.com.br
} 


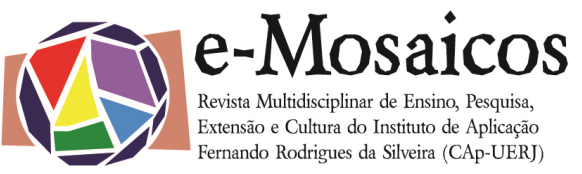

\section{INTRODUÇÃO}

Este artigo propõe uma análise sobre a teoria de um dos mais influentes pensadores das ciências humanas no século XX, Pierre Bourdieu, no que se refere exatamente à área em que mais contribuiu: a educação nas sociedades modernas. Na concepção do autor, aparecem relevantes aspectos sobre a relação entre herança familiar, sobretudo cultural, e desempenho escolar; além de se estabelecer uma considerável relação entre o papel da escola e a reprodução e legitimação das desigualdades sociais no contexto do capitalismo.

Partindo dessas questões teóricas, abordadas nas primeiras quatro partes deste artigo, procuramos trazer alguns aspetos da desigualdade social brasileira, especialmente aquela que atinge a esfera educacional, de maneira a estabelecer uma reflexão dessas desigualdades à luz da teoria crítica bourdiesiana. Essas reflexões aparecem na parte cinco e na conclusão deste artigo, que não pretende fazer uma análise profunda acerca dessa relação e nem sequer a explanação de qualquer verdade numa área polemizada teoricamente e recheada de pesquisas aprofundadas, mas apenas levar o leitor a um pensamento mais cuidadoso sobre a educação e o seu papel nas sociedades modernas.

\section{O pensamento sociológico de Pierre BOURDIEU E O LUGAR DA EDUCAÇÃO}

Elaborando, obra por obra, um sistema completo de análise das relações sociais, Bourdieu desenvolveu uma sociologia que trouxe relevante reflexão crítica em torno das estruturas sociais. Para ele, o papel do sociólogo, enquanto um pesquisador atento das interlocuções sociais, seria o de desvendar o que se passa por trás das estruturas
Paulo Freire.

sociais, identificando os traços invisíveis que não podemos notar através de um simples olhar de senso comum.

Bourdieu elabora, desse modo, um sistema teórico voltado a mostrar como as condições de participação social dos indivíduos baseiam-se na herança social, que se reproduz constantemente numa determinada sociedade - a qual ele chama de estrutura estruturante. Ou seja, a sociedade seria uma estrutura estruturante na medida em que suas mais profundas relações estão constantemente sendo reestruturadas a partir das ações dos seus indivíduos. Assim, o acúmulo dos bens simbólicos, dentre eles a educação, concentra-se nas estruturas do pensamento dos indivíduos, e também nas manifestações externalizadas por suas ações (BOURDIEU, 1989).

É importante dizer que a relação de interdependência entre o conceito de habitus e o conceito de campo é condição para seu pleno entendimento. O conceito de "campo" em Bourdieu representa um espaço marcado pela dominação e pelos conflitos. Como exemplo, podemos citar o campo jornalístico, o campo literário, o campo educacional, dentre muitos outros. Cada campo teria, segundo Bourdieu, uma certa autonomia, possuindo suas próprias regras de organização e de hierarquia social. Dentro desses espaços limitados, os indivíduos atuariam segundo seu capital social, ou seja, as possibilidades que possuem de acordo com a rede de contatos da qual fazem parte.

Ou seja, a teoria praxiológica, ao fugir dos determinismos das práticas, pressupõe uma relação dialética entre sujeito e sociedade, uma relação de mão dupla entre habitus individual e a estrutura de um campo, socialmente determinado. Segundo esse ponto de vista, as ações, comportamentos, 
escolhas ou aspirações individuais não derivam de cálculos ou planejamentos, são, antes, produtos da relação entre um habitus e as pressões e estímulos de uma conjuntura (SETTON, 2002).

É através dos seus habitus que os indivíduos elaboram suas trajetórias e asseguram a reprodução social. Esta reprodução, no entanto, não pode se realizar sem a sutil ação dos agentes e das instituições, preservando as funções sociais por uma forma de dominação simbólica exercida sobre os indivíduos e com a adesão deles. Dessa maneira, um dos primeiros e mais importantes conceitos utilizados por Bourdieu é o de habitus, que é determinado pela posição social do indivíduo na sociedade, posição esta que lhe permite pensar, ver e agir nas mais variadas situações. O habitus traduz, dessa forma, estilos de vida, julgamentos políticos, morais e estéticos, além de ser também um meio de ação que permite criar ou desenvolver estratégias individuais ou coletivas (BOURDIEU, 1989).

Outro conceito muito importante do autor para a finalidade deste artigo consiste no de "capital cultural", bastante utilizado nos seus trabalhos sobre escolaridade. 0 capital cultural refere-se, pois, aos dispositivos técnicos e simbólicos adquiridos pelos sujeitos no meio social. É o conjunto de diplomas, nível de conhecimento geral, experiências com teatro, artes, idiomas e boas maneiras (BOURDIEU, 1998). Este conceito distingue-se de outros dois também de suma importância, o "capital econômico" e o "capital social", sendo o capital econômico relacionado às posses financeiras e os bens portados pelo sujeito, enquanto o capital socia/ vincula-se às redes de relações sociais que este sujeito possui com outros agentes.

Segundo Bourdieu, os estudantes de classe média ou da alta burguesia, pela proximidade com a cultura "erudita", pelas prá- ticas culturais ou linguísticas de seu meio familiar, teriam maior probabilidade de obter o sucesso escolar. Em suas pesquisas na França, Bourdieu procurou demonstrar que existe relação entre a cultura e as desigualdades escolares. Ou seja, a escola pressupõe certas competências que são, de fato, adquiridas na esfera familiar e no meio social do indivíduo. Utilizando-se do conceito de "violência simbólica", o autor busca desvendar os mecanismos que fazem com que os sujeitos aceitem com naturalidade as representações e as ideias dominantes, coordenadas pela burguesia. A violência simbólica, na sua visão, seria desenvolvida pelas instituições e pelos agentes que as põem em prática e sobre a qual se apoiaria o exercício da autoridade (VASCONCELLOS, 2002).

Seria através da transmissão da cultura escolar, a partir especialmente do ambiente da escola, com suas regras, valores e padrões de comportamento, que a classe dominante revelaria a sua violência simbólica sobre alunos das classes populares. Isso ocorreria a partir de conteúdos, programas, métodos de trabalho e de avaliação, relações pedagógicas, práticas linguísticas e temáticas abordadas. Com isso, a violência simbólica se mostraria eficaz, no sentido de explicar a adesão dos dominados pela cultura imposta pelas classes dominantes, na qual se aceitam regras, sanções, regras de direito ou morais e práticas linguísticas.

\section{O PENSAMENTO educacional ante- CEDENTE À BouRdieu}

Bourdieu teve o mérito de formular, a partir dos anos 60, uma resposta original, abrangente e bem fundamentada, teórica e empiricamente, para o problema das desigualdades escolares, especialmente no foco de suas observações. Daí seu paradigma romper com a forma de se abordar as ques- 
tões referentes à educação até então (MARTINS NOGUEIRA; NOGUEIRA, 2002).

Até meados do século $\mathrm{XX}$, predominava, nas Ciências Sociais, uma visão extremamente otimista, de inspiração funcionalistai, que atribuía à escolarização um papel central no duplo processo de superação do atraso econômico, do autoritarismo e dos privilégios, associados às sociedades tradicionais, e de construção de uma nova sociedade. Esta seria justa, baseada na meritocracia; moderna, centrada na razão e nos conhecimentos científicos; e democrática, fundamentada na autonomia individual. Supunha-se que por meio da escola - mesmo pública e gratuita - seria resolvido o problema do acesso à educação, garantindo, dessa maneira, a igualdade de oportunidades entre todos os cidadãos.

O que ocorreu, todavia, nos anos 60, foi uma crise profunda dessa concepção de escola e uma reinterpretação radical do papel dos sistemas de ensino. Abandona-se o otimismo das décadas anteriores, em favor de uma postura bem mais pessimista. Em primeiro lugar, tem-se, a partir do final dos anos 50, a divulgação de uma série de grandes pesquisas quantitativas patrocinadas pelos governos inglês, americano e francês (Aritmética Política inglesa, Relatório Coleman - EUA, Estudos do INED - França) que, em resumo, mostraram, de forma clara, o peso da origem social sobre os destinos escolares. A partir deles, tornou-se imperativo reconhecer que o desempenho escolar não dependia, tão simplesmente, dos dons individuais, mas também da origem social dos alunos, sua classe, etnia, sexo, local de moradia, dentre outros aspectos de ordem social. Em segundo lugar, a mudança no olhar sobre a educação nos anos 60 esteve relacionada a efeitos inesperados da massificação do ensino. Os anos 60 marcam a chegada, ao ensino secundário e à Univer- sidade, da primeira geração beneficiada pela forte expansão do sistema educacional no pós-guerra. Essa geração, reunida em setores mais amplos do que as tradicionais elites escolarizadas, se viu frustrada em suas expectativas de mobilidade social através da escola, devido à desvalorização dos títulos escolares que acompanhou a massificação do ensino na Europa.

Diante dessa crise do paradigma funcionalista, Bourdieu propôs, nos anos 60, outra maneira de se pensar a questão. Os dados que apontavam a forte relação entre desempenho escolar e origem social e que, em última instância, negavam o paradigma funcionalista, transformaram-se nos elementos de sustentação da nova teoria. Onde se via igualdade de oportunidades, meritocracia e justiça social, Bourdieu passou a ver reprodução e legitimação das desigualdades sociais. A educação perderia o papel, que Ihe fora atribuído, de instância transformadora e democratizadora e passaria a ser vista como uma das principais instituições por meio da qual se mantêm e se legitimam os privilégios sociais. Uma das teses centrais da sua Sociologia da Educação é a de que os alunos não são indivíduos abstratos que competem em condições relativamente igualitárias na escola, mas atores socialmente constituídos que traz incorporada, em larga medida, uma bagagem social e cultural diferenciada e mais ou menos rentável no mercado escolar (MARTINS NOGUEIRA; NOGUEIRA, 2002).

Decorrente desta abordagem, Bourdieu lança a concepção de que a escola não é neutra. Formalmente, ela efetivamente trataria a todos de modo igual, na medida em que todos assistiriam às mesmas aulas, seriam submetidos às mesmas formas de avaliação, obedeceriam às mesmas regras e, portanto, teriam as mesmas chances. Contudo, Bourdieu mostra que, na prática, as 
chances são desiguais. Alguns estariam numa condição mais favorável do que outros para atenderem às exigências, muitas vezes implícitas e subliminares, da escola. Ao sublinhar que a cultura escolar é a cultura dominante dissimulada, Bourdieu abre caminho para uma análise mais crítica do currículo, dos métodos pedagógicos e da avaliação escolar, pois os conteúdos curriculares seriam selecionados em função dos conhecimentos, dos valores, e dos interesses das classes dominantes. Como diz o autor:

É provável por um efeito de inércia cultural que continuamos tomando o sistema escolar como um fator de mobilidade social, segundo a ideologia da escola libertadora, quando, ao contrário, tudo tende a mostrar que ele é um dos fatores mais eficazes de conservação social, pois fornece a aparência de legitimidade às desigualdades sociais, e sanciona a herança cultural e o dom social tratado como dom natural (BOURDIEU, 1998, p. 41).

O indivíduo, em Bourdieu, é um ator socialmente configurado em seus mínimos detalhes. Os gostos mais íntimos, as preferências, as aptidões, as posturas corporais, a entonação de voz, as aspirações relativas ao futuro profissional, tudo seria socialmente constituído. A partir de sua formação inicial, em um ambiente social e familiar, os quais correspondem a uma posição específica na estrutura social, os sujeitos incorporariam um conjunto de disposições para a ação típica dessa posição - um habitus familiar ou de classe - que passaria a conduzi-los ao longo do tempo e nos mais variados ambientes de ação. Já a estrutura social se perpetuaria, porque estes próprios sujeitos tenderiam a atualizá-la ao agir de acordo com o conjunto de disposições típicas da posição estrutural na qual eles foram socia- lizados (MARTINS NOGUEIRA; NOGUEIRA, 2002).

Assim sendo, cada ser passa a ser caracterizado por uma bagagem socialmente herdada. Essa bagagem inclui, por um lado, certos componentes objetivos, externos ao sujeito, e que podem ser postos a serviço do sucesso escolar. Fazem parte dessa primeira categoria o capital econômico, tomado em termos dos bens e serviços a que ele dá acesso, o capital social, cuja importância se dá pelo conjunto de relacionamentos sociais influentes mantidos pela família, além do capital cultural institucionalizado, formado basicamente por títulos escolares. As referências culturais, os conhecimentos considerados legítimos e o domínio maior ou menor da língua culta, trazidos de casa por certas crianças, facilitariam o aprendizado escolar, na medida em que funcionariam como uma ponte entre o mundo familiar e a cultura escolar.

Desse modo, é muito importante salientarmos a percepção bourdiesiana de que a educação escolar, no caso das crianças oriundas de meios culturalmente favorecidos, seria uma espécie de continuação da educação familiar, enquanto, para as outras crianças, significaria algo estranho, distante, ou mesmo ameaçador. Nesse tom, a avaliação escolar vai muito além de uma simples verificação de aprendizagem, incluindo um verdadeiro julgamento cultural e até mesmo moral dos alunos. Como diz o autor: Na verdade, cada família transmite
a seus filhos, mais por vias indiretas
que diretas, um certo capital cultu-
ral e um certo ethos, sistema de va-
lores implícitos e profundamente in-
teriorizados, que contribui para de-
finir, entre outras coisas, as atitudes
face ao capital cultural e à institui-
ção escolar. A herança cultural, que
difere, sob dois aspectos, segundo
as classes sociais, é a responsável 
pela diferença inicial das crianças da experiência escolar e, consequentemente, pelas taxas de êxito (BOURDIEU, 1998, p. 42).

Salienta-se que essas exigências só podem ser plenamente atendidas por quem foi previamente socializado nesses mesmos valores. Pode ser na família, ou também através do contato pessoal com amigos e outros parentes que possuam familiaridade com o sistema educacional. Vê-se, neste caso, a importância do capital social como um instrumento de acumulação do capital cultural. Com isso, o capital econômico e o social funcionariam, na maior parte das vezes, apenas como meios auxiliares na acumulação do capital cultural.

\section{O CAPITAL SOCIAL E O CAPITAL CULTURAL NA EDUCAÇÃO}

Retomando o conceito de capital social, este consiste num conjunto de recursos atuais ou potenciais ligados à posse de uma rede durável de relações mais ou menos institucionalizadas de inter-conhecimento e de inter-reconhecimento. Em outras palavras, representa a vinculação a um grupo, como conjunto de agentes que não somente são dotados de propriedades comuns, mas também são unidos por ligações permanentes e úteis. Essas ligações, entretanto, são irredutíveis às relações objetivas de proximidade no espaço geográfico ou no espaço econômico e social, uma vez que são fundadas em trocas inseparavelmente materiais e simbólicas cuja instauração e perpetuação supõem o reconhecimento dessa proximidade pelos agentes participantes (BOURDIEU, 1998).

Importante destacarmos que a existência de uma rede de relações não é exatamente um dado natural, como é o caso do grupo familiar, por exemplo, o qual se defi- ne pela caracterização genealógica que a constitui. Pelo contrário, é produto do trabalho de instauração e manutenção que é necessário para produzir e reproduzir relações duráveis e úteis, com vistas a proporcionar lucros materiais ou simbólicos. A rede de ligações é o produto de estratégias de investimento social consciente ou inconscientemente orientadas para a instituição ou a reprodução de relações sociais. Nela se estabelecem sentimentos de reconhecimento, de respeito, amizade, dentre outros. Estabelecem-se também garantias institucionalizadas, como direitos. Tudo isso, constituído a partir das trocas executadas pelos seus membros, tais como palavras e presentes. Como assegura o autor:
A troca transforma as coisas troca- das em signos de reconhecimento e, mediante o reconhecimento mú- tuo e o reconhecimento da inclusão no grupo que ela implica, produz o grupo e determina ao mesmo tem- po os seus limites, isto é, os limites além dos quais a troca constitutiva, comércio, comensalidade, casamen- to, não pode ocorrer. Cada membro do grupo encontra-se assim instituí- do como guardião dos limites do grupo (BOURDIEU, 1998, p. 68).

Já quanto ao capital cultural incorporado à realidade escolar, distinguem-se três formas sob as quais o capital cultural pode subsistir: no estado incorporado, no estado objetivado e no estado institucionalizado (BOURDIEU, 1998).

No estado incorporado, o capital cultural aparece sob a forma de disposições duráveis no organismo do próprio indivíduo. É um ter que se tornou ser, uma propriedade que se fez corpo e tornou-se parte integrante da pessoa, um habitus. Este capital não pode ser transmitido instantaneamente, 
diferentemente do dinheiro ou de um título de nobreza, mas se adquire de uma forma totalmente dissimulada e inconsciente. Como diz: "Não pode ser acumulado para além das capacidades de apropriação de um agente singular; depaupera e morre com seu portador, com suas capacidades biológicas, sua memória, etc" (BOURDIEU, 1998, p. 75).

Já no estado objetivado, aparecem sob a forma de bens culturais, como quadros, livros, dicionários, instrumentos e máquinas. O capital cultural, no estado objetivado, detém um certo número de propriedades que se define apenas em sua relação com o capital cultural em sua forma incorporada. Como diz:

O capital cultural no estado objetivado apresenta-se com todas as aparências de um universo autônomo e coerente que, apesar de ser o produto da ação histórica, tem suas próprias leis, transcendentes às vontades individuais, e que permanece irredutível, por isso mesmo, àquilo que cada agente ou mesmo o conjunto dos agentes pode se apropriar (BOURDIEU, 1998, p. 78).

E quanto à sua existência, diz:

É preciso não esquecer, todavia, que ele só existe e subsiste como capital ativo e atuante, de forma material e simbólica, na condição de ser apropriado pelos agentes e utilizado como arma e objeto às lutas que se travam no campo da produção cultural (campo artístico, científico, etc.) e, para além desses, no campo das classes sociais, onde os agentes obtêm benefícios proporcionais ao domínio que possuem desse capital objetivado, portanto, na medida de seu capital incorporado (BOURDIEU, 1998, p. 78).
Por fim, o estado institucionalizado é um tipo de forma de objetivação que é preciso ser colocado à parte, uma vez que confere ao capital cultural propriedades inteiramente originais. Segundo diz:
Ao conferir ao capital cultural pos- suído por determinado agente um reconhecimento institucional, o cer- tificado escolar permite, além disso, a comparação entre os diplomados e, até mesmo, sua 'permuta' (subs- tituindo-os uns pelos outros na su- cessão); permite também estabele- cer taxas de convertibilidade entre o capital cultural e o capital econômi- co, garantindo o valor em dinheiro de determinado capital escolar (BOURDIEU, 1998, p. 79).

\section{O INVESTIMENTO NA EDUCAÇÃo DE ACORDO COM A CLASSE SOCIAL}

Bourdieu distingue três conjuntos de disposições e de estratégias de investimento escolar os quais seriam adotados tendencialmente pelas classes populares, classes médias (ou pequena burguesia) e pelas elites (MARTINS NOGUEIRA; NOGUEIRA, 2002).

O primeiro desses grupos, pobre em capital econômico e cultural, tenderia a investir de modo moderado no sistema de ensino. Seria um investimento relativamente baixo, o que se explicaria por várias razões. Em primeiro lugar, devido à percepção, a partir dos exemplos acumulados, de que as chances de sucesso são reduzidas, na medida em que faltariam os recursos econômicos, sociais e, sobretudo, culturais necessários para um bom desempenho escolar. Isso tornaria o retorno do investimento muito incerto e, portanto, o risco muito alto. Essa incerteza e esse risco seriam ainda maiores 
pelo fato de que o retorno do investimento escolar é dado no longo prazo, sendo que essas famílias estariam, em função de sua condição socioeconômica, menos preparadas para suportar os custos econômicos dessa espera. Seria um pesado fardo, por exemplo, o adiamento da entrada dos filhos no mercado de trabalho, fator necessário para se adquirir a qualificação exigida para altas funções.

Acrescenta-se a isso o fato de que o retorno alcançado com os títulos escolares depende, parcialmente, como já foi dito anteriormente, da posse de recursos econômicos e sociais passíveis de serem mobilizados para potencializar o valor dos títulos. No caso dessas famílias, nas quais esses recursos são reduzidos. Segundo Bourdieu, nessas famílias, de um modo geral, a vida escolar dos filhos não seria acompanhada de modo muito sistemático e nem haveria uma cobrança intensiva em relação ao sucesso escolar. As aspirações escolares desse grupo seriam moderadas, esperando dos filhos que eles estudassem apenas o suficiente para se manter. Esse estágio de educação já significaria, na maioria dos casos, o alcance de uma escolarização superior à dos pais. Essas famílias tenderiam, assim, a privilegiar as carreiras escolares mais curtas, que dão acesso mais rapidamente à inserção profissional. Um investimento numa carreira mais longa só seria feito nos casos em que a criança apresentasse, precocemente, resultados escolares excepcionalmente positivos, capazes de justificar a aposta arriscada no investimento escolar.

Já as classes médias - ou pequena burguesia, segundo a expressão de Bourdieu -, tenderiam a investir pesada e sistematicamente na escolarização dos filhos. Esse comportamento se explicaria, em primeiro lugar, pelas chances objetivamente superiores dos filhos das classes médias alcança- rem o sucesso escolar. As famílias desse grupo social já possuiriam um volume razoável de capitais que lhes permitiriam apostar no mercado escolar sem correr tantos riscos. Para Bourdieu, no entanto, o comportamento das famílias das classes médias não pode ser explicado apenas pelas chances comparativamente superiores de seus filhos. Seria necessário considerar, igualmente, as expectativas quanto ao futuro, sustentadas por esses grupos sociais. Originárias, em grande parte, das camadas populares e tendo ascendido às classes médias por meio da escolarização, as famílias de classe média nutririam esperanças de continuarem sua ascensão social, agora, em direção às elites.

Todas as condutas das classes médias poderiam ser entendidas, dessa maneira, como parte de um esforço mais amplo com vistas a criar condições favoráveis à ascensão social. Nessas classes sociais seria normal evidenciar determinadas disposições de renunciarem aos prazeres imediatos, em benefício do seu projeto de futuro, especialmente dos filhos. Sacrificariam a compra de bens materiais e viagens, por exemplo, de modo a investirem na boa escolarização dos seus filhos.

Além disso, a classe média tenderia a controlar a fecundidade, desenvolvendo a estratégia de concentrar os recursos num número reduzido de filhos. Embora, de um modo geral, possa se falar que a aspiração por ascensão social, que caracteriza as classes médias, conduz à tendência de se investir fortemente na escolarização dos filhos, não se pode esquecer que o grau em que isso ocorre dependeria do peso relativo dos capitais em cada uma das frações da classe média. As frações mais providas de capital econômico - ao contrário das que possuem quase que exclusivamente capital cultural tenderiam a não conceder uma prioridade tão acentuada ao investimento escolar. Se- 
ria necessário observar, também, que a tendência maior ou menor ao investimento escolar estaria relacionada com a trajetória ascendente ou descendente da fração de classe média em questão. Nesse sentido, os grupos ascendentes seriam os que depositariam maiores esperanças na escolarização de seus filhos.

Por fim, Bourdieu se refere às elites econômicas. Esses grupos investiriam pesadamente na escola, porém, de uma forma bem mais descontraída do que as classes médias. Isso se deveria, por um lado, ao fato de que o sucesso escolar no caso dessas famílias é tido como algo natural, que não depende de um grande esforço de mobilização familiar. As condições objetivas, tais como a posse de um volume expressivo de capitais econômicos, sociais e culturais, tornariam o fracasso escolar bastante improvável. Ademais, as elites estariam livres da luta pela ascensão social. Elas já ocupam as posições dominantes, não dependendo, portanto, do sucesso escolar dos filhos para ascender socialmente.

Em relação às elites, importante salientar que Bourdieu contrasta as frações mais ricas em capital cultural com aquelas mais ricas em capital econômico. As primeiras seriam propensas a um investimento escolar mais intenso, visando o acesso às carreiras mais longas e prestigiosas do sistema de ensino. Já as frações mais ricas em capital econômico tenderiam a buscar na escola, principalmente, uma certificação que legitimaria o acesso às posições de controle já garantidas pelo capital econômico.

\section{BREVe REFLEXÃo dAS DESigualdades SOCIOEDUCACIONAIS NO BRASIL À LUZ DE BOURDIEU}

A história do Brasil mostra como as desigualdades sociais foram se reproduzindo pelos séculos e pelas últimas décadas a partir, sobretudo, da reprodução de classes. Nesse sentido, a contribuição crítica de Bourdieu pode ser de extrema relevância para uma análise da realidade brasileira. As elites sempre desenvolveram mecanismos que lhes assegurassem a permanência nas posições de origem ascendente. A própria circulação dentro da estrutura social brasileira não foi capaz de reduzir em grandes escalas a desigualdade que o século XX herdou do passado escravista. Não se pode negar que pobres e negros tiveram mobilidade entre gerações, mas isso foi muito mais caracterizado por uma passagem da área rural para o meio urbano, do que propriamente representou consideráveis ganhos em relação à hierarquia social (RIBEIRO, 2007).

O modelo rural, formador da sociedade brasileira, tinha como fortes traços a desigualdade, que aparecia na concentração de terras, nas influências econômicas e políticas e no despreparo de grande parte dos trabalhadores. Foi exatamente essa população desprivilegiada do Brasil rural aquela que mais sofreu com os efeitos do rápido processo de industrialização e urbanização. Muitos de seus filhos foram viver nas cidades, mas sentiram na pele o peso da origem, seja través do preconceito da origem racial, seja através do preconceito da falta de conhecimentos técnicos para se empregarem nos novos ramos fabris existentes (RIBEIRO, 2007).

Abaixo, tabela que mostra a distribuição do rendimento segundo a cor em 1999 e 2009, demonstrando como os negros seguem, no período atual, em consideráveis desvantagens econômicas em relação aos brancos e como a riqueza no Brasil segue concentrada em benefício de pequenos grupos.

Além disso, o crescimento do sistema 
educacional, ao longo do século XX, também foi bastante lento. Nas décadas de 1960 e 1970, para se ter uma ideia - período considerado como o auge da industrialização -, as universidades e as escolas de nível secundário (atual ensino médio), cresceram mais que o ensino básico. Com isso, a maior parte da população desprovida economicamente e que vinha da área rural para a área urbana não conseguiu ingressar no sistema escolar básico. Apenas mais recentemente, a partir da década de 1990, pudemos verificar um efetivo aumento do ensino básico no Brasil, caminhando para a universalização do ensino nesta faixa etária. A educação, dessa maneira, permaneceu como fonte de acesso à reduzida parcela privilegiada da população durante boa parte do século passado (RIBEIRO, 2007).

Vejamos dados atuais, que mostram menos negros (pretos e pardos) no ensino superior, se comparados aos brancos. Ou seja, a educação superior continua consideravelmente segregada em favor de grupos racialmente definidos e de condições econômicas determinadas:

\section{Tabela 1:}

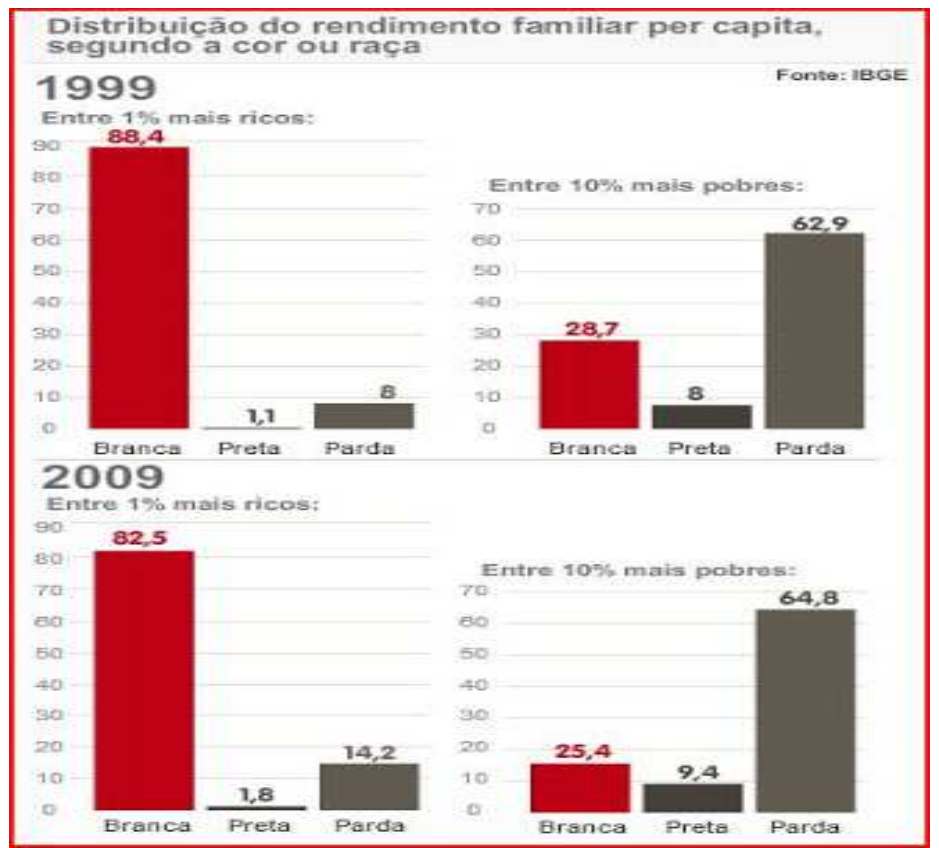

Fonte: IBGE. Disponível em: http://picasaweb.google.com/lh/photo/ srV_B5CqtR1tCkPbIEjb5Q?feat=embedwebsite>.

Além disso, o crescimento do sistema educacional, ao longo do século XX, também foi bastante lento. Nas décadas de 1960 e 1970, para se ter uma ideia - perío- do considerado como o auge da industrialização -, as universidades e as escolas de nível secundário (atual ensino médio), cresceram mais que o ensino básico. Com isso, 
a maior parte da população desprovida economicamente e que vinha da área rural para a área urbana não conseguiu ingressar no sistema escolar básico. Apenas mais recentemente, a partir da década de 1990, pudemos verificar um efetivo aumento do ensino básico no Brasil, caminhando para a universalização do ensino nesta faixa etária. A educação, dessa maneira, permaneceu como fonte de acesso à reduzida parcela privilegiada da população durante boa parte do século passado (RIBEIRO, 2007).

Vejamos dados atuais, que mostram menos negros (pretos e pardos) no ensino superior, se comparados aos brancos. Ou seja, a educação superior continua consideravelmente segregada em favor de grupos racialmente definidos e de condições econômicas determinadas:

\title{
Tabela 2:
}

\begin{abstract}
Distribuição dos brasileiros de 15 a 24 anos de idade que frequentavam escola, por cor ou raça, segundo o nivel de ensino (em \%)
\end{abstract}

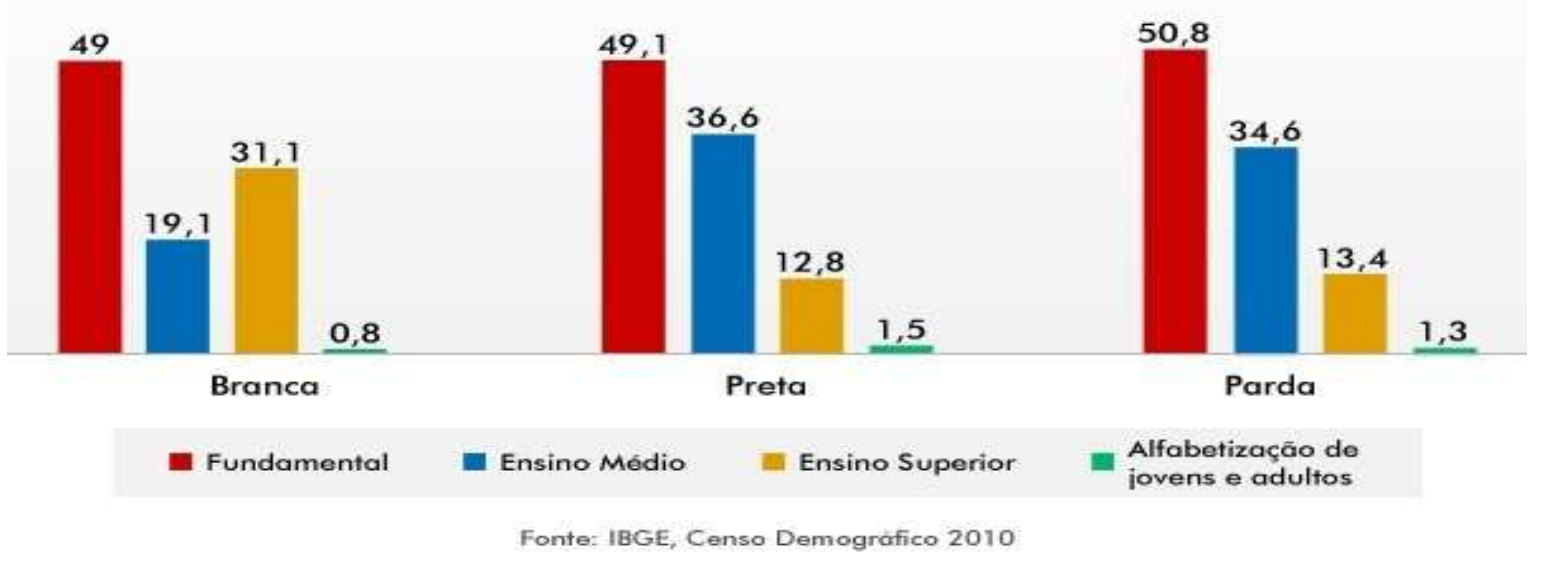

Disponível em:

<http://noticias.uol.com.br/cotidiano/ultimas-noticias/2012/06/29/brancos-ganham-duas-vezes-mais-quenegros-e-dominam-ensino-superior-no-pais-mostra-censo-2010.htm>.

Numa linguagem bourdiesiana, a violência simbólica presente na estrutura social brasileira a dividiu em classes bem definidas, sustentando-as segundo o preconceito e a segregação. Nesta sociedade, o poder simbólico do capital econômico sempre exerceu considerável poder que se espalhou para os demais campos de vínculos sociais, tais como relações profissionais, políticas e culturais. Os hábitos cultivados pelas elites acabaram se envolvendo com a ideia de que estes seriam os melhores hábitos, e os estilos de vida dessa classe marcou profundamente os principais espaços de interação social no país.

Nesse contexto, a educação foi se desenvolvendo, inicialmente, como fonte de acesso aos membros dessas elites, que nela 
viram a possibilidade de ganhos de status e aquisição de um capital cultural que se juntaria ao capital econômico já portado por suas famílias. Com o avanço das taxas de escolarização, hoje em dia a educação no Brasil de qualidade, a despeito dos projetos de universalização da alfabetização, é privilégio de poucos que podem efetivamente arcar com seus altos custos.

Assim sendo, o capital cultural, indispensável para uma boa evolução na aprendizagem e no aprimoramento do conhecimento acerca do mundo a nossa volta, acaba por vincular-se diretamente às posses provenientes das condições de classe. Isso explica boa parte da relação proporcionalmente crescente entre a condição de renda per capita dos estudantes e o avanço nas transições escolares, e a manutenção das desigualdades educacionais no país. Portanto, a partir destas desigualdades, explica-se como que, num país de fortes gradações de qualidade escolar, as desigualdades de renda e de cor persistem consideravelmente, mesmo após termos verificado um aumento considerável no acesso à educação, em todas as faixas, nos últimos anos.

Vinculado a esses dois tipos de aportes sociológicos - o capital econômico e o capital cultural - podemos nos inspirar em Bourdieu para identificarmos a forte presença, no Brasil, do capital social. Este aporte, caracterizado pelas redes de contatos estabelecidas pelos agentes da estrutura social, foi e continua sendo aspecto de relevante centralidade para a manutenção das desigualdades de classe. As redes sociais das pessoas com capital econômico e capital cultural intensos são mais amplas e mais articuladas do que daqueles que detém menores capitais desses tipos. Aí atua a violência simbólica que acomete a sociedade brasileira, reestruturando uma realidade desigual em seus aspectos de classe e de raça, e que a educação apresentaria pouca força para alterar.

É com isso que podemos propor uma leitura reflexiva acerca dos projetos de ações afirmativas que vêm sendo implementados no Brasil, já que têm se configurado como as principais políticas voltadas para a redução das desigualdades raciais. Até que ponto as ações afirmativas ${ }^{i i}$, ao darem maior possibilidade de acesso a cargos, empregos e vagas nas universidades - através das cotas universitárias -, efetivamente serão capazes de reduzir as desigualdades que acometem grupos segregados, como a imensa população negra? Embora a pretensão seja dar um suporte aos beneficiados, ligando-os ao capital econômico, cultural e social das elites, será necessário que as pessoas beneficiadas consigam transmitir aos seus filhos os mesmos capitais necessários para chegarem aos patamares alcançados pelos pais sem a necessidade da mesma reserva de vagas.

Nesse sentido, Bourdieu nos permite pensar que as atuais políticas de justiça social podem estar apenas tentando ajustar a estrutura social existente, em busca de justiça e redução das desigualdades, mas sem alterar a estrutura que gerou as próprias desigualdades. Assim sendo, o Brasil pode estar mantendo as mesmas desigualdades que historicamente apresentou, apenas reduzindo-as um pouco, porém sob o manto das políticas de igualização e da preocupação com os índices de melhorias sociais que não transformariam a sua estrutura efetivamente desigual.

\section{CONCLUSÃo}

Apesar de os trabalhos de Bourdieu terem revelado as limitações da educação, enquanto portadora de um papel revolucionário, devemos ressalvar que a crença na 
educação permanece bastante viva na literatura pedagógica, nas políticas públicas e no inconsciente coletivo. No Brasil, a educação, enquanto potencializadora de transformação, continua em destaque, especialmente nos círculos públicos que envolvem os debates políticos. Defende-se que através do crescimento educacional o país poderá gerar uma massa mais consciente politicamente, mais qualificada profissionalmente e mais avançada moralmente. Entretanto, o que os debates políticos não mostram são os limites da própria educação dentro de uma sociedade hierarquizada, do ponto de vista de vários capitais indispensáveis para os efeitos pretendidos através do investimento em educação.

No século $X X$, pouco depois do fim da abolição, foram chegando propostas e ideias de modernização ao país, mas junto houve a persistência de uma complexa teia de tradicionalismo político, social e econômico, que persiste até hoje em nossas vidas, tecendo um país contraditório: rico porém desigual. $\mathrm{A}$ educação aparece no seio dessas contradições, haja vista as desigualdades que acompanham o seu processo. As melhores escolas normalmente são pagas, e são quase que exclusivamente acessíveis às classes médias e altas. Seus alunos, em grande medida, trazem consigo toda uma conjunção de capitais indispensáveis para o sucesso educacional. Por outro lado, o ensino público geralmente apresenta uma série de problemas, desde a falta de infraestrutura adequada, até a má remuneração do corpo docente. No momento de concorrer às vagas dos melhores cursos e nas melhores faculdades, os indivíduos mais bem preparados levam vantagens, contestando a aparente e enganosa igualdade meritocrática de oportunidades.

Aceitemos ou não a leitura de Bourdieu para analisar as questões atuais do Brasil, podemos, sem sombra de dúvidas, usar sua teoria para pensarmos a educação e o seu real papel transformador nas sociedades modernas. Sem nos prendermos a uma cadeia pessimista, mas procurando nos desprender dela, alguma reflexão certamente poderá nos ajudar a melhorar nossa atuação enquanto profissionais da educação.

\section{REFERÊNCIAS BIBLIOGRÁFICAS:}

BOURDIEU, Pierre. Escritos de Educação. Petrópolis: Vozes, 1998.

O Poder Simbólico. Rio de Janeiro: Editora Bertrand Brasil S.A, 1989.

ciologia. ORTIZ, Renato (org.). São Paulo: Ática, 1983.

MARTINS NOGUEIRA, Cláudio Marques; NOGUEIRA, Maria Alice. "A sociologia da educação de Pierre Bourdieu: Limites e contribuições". In: Revista Educação e Sociedade, vol. 23, no 78, Campinas, 2002.

RIBEIRO, Carlos Antônio Costa. Estrutura de classe e mobilidade social no Brasil. Bauru, SO: Edusc, 2007.

SETTON, Maria da Graça Jacintho. "A teoria do habitus em Pierre Bourdieu: uma leitura contemporânea". In: Revista Brasileira de Educação, nº 20, Maio/Jun/Jul/Ago, 2002.

VASCONCELLOS, Maria Drosila. "Pierre Bourdieu: a herança sociológica". In: Educação \& Sociedade, vol. 23, no 78, abril, Campinas, 2002.

VIEIRA DA COSTA, Andréa Lopes. Ação Afirmativa e o Combate as Desigualdades Raciais no Brasil: Em busca do Caminho das Pedras. Tese de Doutorado, IUPERJ: 2005. 
i Émile Durkheim foi um dos expoentes do funcionalismo. A educação, segundo Durkheim, transmitiria valores morais que integram a sociedade, sendo a coesão social o aspecto de sua maior preocupação. $\mathrm{O}$ autor destaca a função uniformizadora e diferenciadora da educação: de um lado, visando a integração do indivíduo no contexto social, transmitindo valores e desenvolvendo atitudes comuns; de outro lado, a educação diferenciadora, respondendo à divisão social do trabalho e reforçando-a. No Brasil, este paradigma do consenso influenciou especialmente a obra de Fernando Azevedo, sociólogo inspirado na teoria durkheimiana. Azevedo foi o pioneiro da Escola Nova, movimento que nas primeiras décadas do século XX defendia a universalização da escola pública, laica e gratuita. Segundo defendia, os sistemas educativos variam de acordo com as formas de sociedade, só sendo compreendidos, pois, em função do todo. Assim, ele destaca o papel socializador da educação, seu caráter coercitivo, sua importância para a integração social e as relações entre mudança social e educacional. No Brasil em que viveu, marcado pela emergência da sociedade urbano-industrial, uma de suas grandes preocupações foi o ajustamento da educação às novas condições histórico-sociais.

ii Ótimo estudo sobre as ações afirmativas, Cf. VIEIRA DA COSTA, Andréa Lopes. Ação Afirmativa e o Combate as Desigualdades Raciais no Brasil: Em busca do Caminho das Pedras. Tese de Doutorado, IUPERJ: 2005. 